\title{
Acknowledgments
}

I undertook this collection thinking it would be a quick and easy endeavor-a cleansing of the palate, if you will-after the long and arduous task of completing a single-author book. After putting this project aside multiple times to attend to various pressing demands, I looked up and realized that nearly a dozen scholarly books had been published on the topic of television in the digital age. The presence of such strong and compelling works - all from unique and valuable perspectives-made the task of compiling this collection that much more daunting. Therefore, I'd like to thank the first-rate editorial team at Rutgers University Press and give a special acknowledgment to editor Leslie Mitchner for her early support of the project in its proposal stage and for her helpful comments, encouragement, and provocative suggestions on the manuscript when I finally delivered it.

Situating this project in such a cluttered research space was made easier because of the original and insightful work of my contributors. In particular, I'd like to single out Henry Jenkins, who added yet another responsibility to his already overflowing "to do" box by agreeing to co-chair our annual Transmedia Hollywood conference. This forum provided the perfect backdrop for researching this book's themes by bringing together cutting-edge media makers and thought leaders from diverse corners of the entertainment industry and academia to debate issues attending the future of entertainment. The first conference year was the most daunting. We had timed our launch in Los Angeles to coincide with the arrival of hundreds of media scholars in March 2010 to attend the annual Society of Cinema and Media Studies (SCMS) conference. Given our zealous desire to share the riches of our proximity to Hollywood, we also assembled a SCMS workshop at the Bonaventura Hotel and dubbed it "The Geek Elite Debates the Future of Entertainment." The workshop convened a truly elite group of television writer-producers-Carlton 
Cuse and Damon Lindelof (Lost), Tim Kring (Heroes), Kim Moses (The Ghost Whisperer), Javier Grillo-Marxuach (The Middleman), and Mark Warshaw (Smallville, Heroes). All of them were laboring over the central questions that inform this collection: how to challenge themselves and their creative teams to embrace the transformative implications of the Internet and Web 2.0 in the context of an often rigid, opaque, and risk-adverse bureaucratic system like the network television industry. I remain indebted to each of these prominent creators for their ongoing support as I continued to ply them with questions and requests for follow-up interviews while assembling this collection.

Next, I'd like to thank my UCLA colleagues: Teri Schwartz, dean of the School of Theater, Film, and Television, and William McDonald, chair of the Department of Film, TV, and Digital Media; my immediate workplace family, UCLA Producers Program faculty members Barbara Boyle, Ben Harris, and Myrl Schreibman, as well as my extended workplace family of over thirty busy, top-tier industry professionals, who agree to teach classes on behalf of our next-generation producers. I'd like to thank my adopted workplace family, the Cinema and Media Studies faculty members Janet Bergstrom, John Caldwell, Allyson Fields, Stephen Mamber, and Chon Noriega. In addition, I'd like to thank all the MA, MFA, and PhD students at UCLA for their direct and indirect contributions to this project through their insightful works and original ideas delivered during my seminars. In particular, I'd like to thank my research assistant and doctoral student Jessica Fowler for her careful copyediting and helpful suggestions. In addition, I'd like to thank several current and recent UCLA doctoral students-M. J. Clarke, Lindsay Giggey, Felicia Henderson, Drew Morton, Jennifer Porst, and Ben Sampson - whose exacting research and writing on the contemporary entertainment industry make teaching such a continued source of pleasure. 


\section{Wired TV}


